\title{
Intratumoral genetic heterogeneity in pilocytic astrocytomas revealed by CGH-analysis of microdissected tumor cells and FISH on tumor tissue sections
}

\author{
SILKE WEMMERT $^{1}$, BERND F.M. ROMEIKE ${ }^{2}$, RALF KETTER ${ }^{1}$, WOLF-INGO STEUDEL ${ }^{1}$, \\ KLAUS D. ZANG ${ }^{3}$ and STEFFI URBSCHAT ${ }^{1}$ \\ ${ }^{1}$ Department of Neurosurgery, ${ }^{2}$ Institute of Neuropathology and ${ }^{3}$ the Institute of Human Genetics, \\ Saarland University, D-66421 Homburg/Saar, Germany
}

Received September 8, 2005; Accepted November 27, 2005

\begin{abstract}
Pilocytic astrocytomas are the most frequent gliomas of childhood. The majority of cases show cytogenetic normal karyotypes. Although in diffuse gliomas TP53 gene mutations or deletions occur with significant frequency, the role in pilocytic astrocytomas remains unclear. Histomorphologically different areas of 14 pilocytic astrocytomas were microdissected and analyzed for genetic aberrations and heterogeneity. CGH analysis revealed gains of chromosome arm 4q and 6q mainly in areas of classic biphasic pattern, whereas pleomorphic areas presented gains of chromosome 6 and 8q. Using two-color fluorescence in situ hybridization (FISH) the spatial distribution of aneuploidies for chromosomes 7, 8, 17 and the TP53 gene were assessed on parallel sections. FISH analysis revealed a significant percentage of cells with interspersed heterozygous deletions of TP53 in all tumors (14/14), ten cases showed also monosomy 17. Besides gains of chromosomes 7 and 8 , losses of these chromosomes were detected in the majority of tumors. In conclusion, pilocytic astrocytomas show a genetic heterogeneity associated with variations of histologic structure as well as an intratumoral heterogeneity observed on single cell level by FISH.
\end{abstract}

\section{Introduction}

Pilocytic astrocytomas are the most frequent gliomas in children and young adults. They are classified as grade I by the World Health Organization (WHO) and do not generally tend to evolve into higher grade tumors. Pilocytic astrocytomas differ from other gliomas significantly in clinical behavior. In general, they have a favorable prognosis and do not show most of the genetic changes seen in diffuse astrocytomas.

Correspondence to: Dr Steffi Urbschat, Neurooncology, Institute of Human Genetics, Saarland University, Bldg. 60, D-66421 Homburg/Saar, Germany

E-mail: hgsmur@uniklinik-saarland.de

Key words: CGH, FISH, heterogeneity, microdissection, pilocytic astrocytoma
Histomorphologically, they are characterized by a biphasic pattern. Areas with bipolar cells forming a dense fibrillary background with Rosenthal fibers and with loose stellate cells in a microcystic background. Pilocytic astrocytomas show also pleomorphic areas, however, pleomorphism does not indicate malignancy in this tumor (1-3).

Previous reports on the cytogenetics of pilocytic astrocytomas have suggested no consistent or characteristic genetic abnormalities. Numeric abnormalities described are gains of chromosome 7 and gains or losses of chromosomes 8 and 11 (4-11). Less often complex clonal abnormalities were observed in these tumors $(4,11)$ suggesting a genetic heterogeneity.

Comparative genomic hybridization analysis (CGH) showed similar results, affecting several chromosomes including aneuploidy for chromosomes 7 and 8 (12-15). Fluorescence in situ hybridization (FISH) on isolated nuclei from paraffin embedded material revealed comparable results (16).

Conflicting data are reported for the role of the TP53 gene which is often mutated or deleted in other tumors, particularly in diffuse gliomas. The reported mutation rate of TP53 in pilocytic astrocytomas varies between 0 and $35 \%(3,17-21)$.

Losses on 17q have also been described and in some cases these encompass the NF1 locus (neurofibromatosis type 1 gene) $(22,23)$. However, no NF1 mutations were observed by single-strand conformation polymorphism analysis of 16 pilocytic astrocytomas (24).

Because some of these inconsistencies might be due to genetic heterogeneity, CGH analysis was performed on microdissected tumor tissue in order to test for different genetic changes in morphologically different areas, which cannot be distinguished by investigation of tumor-homogenates. The same objective was applied to investigate paraffin-embedded tumor tissue by FISH analysis with centromere-specific probes for chromosomes 7,8 and 17 and a single copy probe for TP53, due to inconsistent results of cell culture and to detect chromosomal aberrations which occur only in a minority of cells.

Patients and methods

Patients and tumor probes. A total of 21 pilocytic astrocytomas from 17 patients were analyzed. Hematoxylin and eosin 
Table I. Clinical data and CGH results of 14 microdissected pilocytic astrocytoma.

\begin{tabular}{|c|c|c|c|c|}
\hline Tumor no. & Age/sex ${ }^{a}$ & Tumor site & Area & CGH karyotype of microdissected probe ${ }^{b}$ \\
\hline $234 / 92$ & $15 / \mathrm{m}$ & Cerebellum & $\begin{array}{l}\text { Control } \\
\text { Biphasic } \\
\text { Pleomorphic }\end{array}$ & $\begin{array}{l}46, X Y \\
46, X Y \\
\text { rev ish dim }(Y)\end{array}$ \\
\hline $486 / 93$ & $15 / \mathrm{m}$ & Supratentorial & $\begin{array}{l}\text { Control } \\
\text { Biphasic } \\
\text { Pleomorphic }\end{array}$ & $\begin{array}{l}46, X Y \\
\text { rev ish enh }(7 \mathrm{p} 14 \mathrm{p} 21,7 \mathrm{q} 31 \mathrm{q} 35) \\
\text { rev ish enh }(2 \mathrm{q} 24 \mathrm{q} 34,4 \mathrm{q} 22 \mathrm{q} 31,5 \mathrm{q} 21,6 \mathrm{q} 13 \mathrm{q} 23,12 \mathrm{q} 14 \mathrm{q} 22,13 \mathrm{q} 21 \mathrm{q} 22) \\
\text { rev ish dim (1p36pter,17p13pter,18p11.2,19,22q11q12) }\end{array}$ \\
\hline $91 / 94$ & $28 / \mathrm{m}$ & Cerebellum & $\begin{array}{l}\text { Control } \\
\text { Pleomorphic }\end{array}$ & $\begin{array}{l}46, X Y \\
\text { rev ish enh }(8 q)\end{array}$ \\
\hline $287 / 94$ & $2 / f$ & Cerebellum & $\begin{array}{l}\text { Control } \\
\text { Biphasic }\end{array}$ & $\begin{array}{l}46, X X \\
\text { rev ish enh }(4 q, 5 q, 6 q, 11 q) \\
\text { rev ish } \operatorname{dim}(19 p)\end{array}$ \\
\hline $1474 / 94$ & $4 / \mathrm{m}$ & Supratentorial & $\begin{array}{l}\text { Biphasic } \\
\text { Pleomorphic }\end{array}$ & $\begin{array}{l}46, X Y \\
46, X Y\end{array}$ \\
\hline $\begin{array}{l}363 / 99 \\
\text { Recurrence } \\
\text { of } 1474 / 94\end{array}$ & $8 / \mathrm{m}$ & Supratentorial & $\begin{array}{l}\text { Control } \\
\text { Biphasic } \\
\text { Pleomorphic }\end{array}$ & $\begin{array}{l}46, X Y \\
\text { rev ish enh }(3 \mathrm{p} 24 \mathrm{pter}, 10 \mathrm{q} 26) \\
\text { rev ish enh }(\mathrm{X}) \\
\text { rev ish } \operatorname{dim}(\mathrm{Y})\end{array}$ \\
\hline $357 / 96$ & $7 / \mathrm{m}$ & Cerebellum & $\begin{array}{l}\text { Control } \\
\text { Biphasic }\end{array}$ & $\begin{array}{l}46, X Y \\
\text { rev ish enh }(4 q, 6 q)\end{array}$ \\
\hline $752 / 96$ & $8 / \mathrm{m}$ & Cerebellum & $\begin{array}{l}\text { Control } \\
\text { Biphasic } \\
\text { Pleomorphic }\end{array}$ & $\begin{array}{l}46, X Y \\
\text { rev ish } \operatorname{dim}(Y) \\
\text { rev ish enh }(6 q, 8,18 q, X) \\
\text { rev ish } \operatorname{dim}(Y)\end{array}$ \\
\hline $\begin{array}{l}1054 / 97 \\
\text { Recurrence } \\
\text { of } 752 / 96\end{array}$ & $9 / \mathrm{m}$ & Cerebellum & Biphasic & rev ish enh $(8 \mathrm{q}, \mathrm{X})$ \\
\hline $57 / 97$ & $14 / \mathrm{f}$ & Spinal & $\begin{array}{l}\text { Control } \\
\text { Biphasic }\end{array}$ & $\begin{array}{l}46, X X \\
\text { rev ish enh (6q12q21,7q11q21,12q12q21) } \\
\text { rev ish dim (9p21pter,10p21pter) }\end{array}$ \\
\hline $122 / 97$ & $2 / f$ & Cerebellum & $\begin{array}{l}\text { Control } \\
\text { Biphasic }\end{array}$ & $\begin{array}{l}\quad 46, X X \\
\text { rev ish enh }(4 q) \\
\text { rev ish } \operatorname{dim}(16 q)\end{array}$ \\
\hline 223/99 & $16 / \mathrm{m}$ & Brainstem & Biphasic & rev ish enh (4q31qter,12q24qter) \\
\hline $1244 / 99$ & $3 / f$ & Spinal & $\begin{array}{l}\text { Control } \\
\text { Biphasic } \\
\text { Pleomorphic }\end{array}$ & $\begin{array}{l}46, X X \\
46, X X \\
\text { rev ish enh }(6 \mathrm{p} 12 \mathrm{p} 22,8 \mathrm{q} 24)\end{array}$ \\
\hline $\begin{array}{l}638 / 00 \\
\text { Recurrence } \\
\text { of } 1244 / 99\end{array}$ & $4 / f$ & Spinal & $\begin{array}{l}\text { Biphasic } \\
\text { Pleomorphic }\end{array}$ & $\begin{array}{l}46, X X \\
\text { rev ish enh (4p16,5q31qter,6p21,8q24qter,11q12,12q24,20) }\end{array}$ \\
\hline
\end{tabular}

${ }^{\mathrm{a}} \mathrm{m}$, male; f, female. ${ }^{\mathrm{b}}$ The description of karyotypes is based on the ISCN (Mitelman, 1995): rev ish, reverse in situ hybridization; enh, enhanced; dim, diminished.

(HE)-stained sections were classified according to the World Health Organization (WHO) classification (2), by one of the authors. None of the patients had a known association with a type I neurofibromatosis. The study was approved by the local Ethics comittee. Specific informed consent was obtained. 
Table II. Results of interphase cytogenetics in pilocytic astrocytomas (in \% of nuclei evaluated per slide).

\begin{tabular}{|c|c|c|c|c|c|c|c|c|c|c|c|c|c|c|c|}
\hline \multirow{2}{*}{$\begin{array}{l}\text { Tumor no. } \\
\text { Age/sex } \\
\text { Tumor site }\end{array}$} & \multirow{2}{*}{$\begin{array}{l}\text { Chromo- } \\
\text { some } \\
\text { probe }\end{array}$} & \multicolumn{6}{|c|}{ Number of signals } & \multirow{2}{*}{$\begin{array}{l}\text { Tumor no. } \\
\text { Age/sex }{ }^{\mathrm{a}} \\
\text { Tumor site }\end{array}$} & \multirow{2}{*}{$\begin{array}{c}\text { Chromo- } \\
\text { some } \\
\text { probe }\end{array}$} & \multicolumn{6}{|c|}{ Number of signals } \\
\hline & & 0 & 1 & 2 & 3 & 4 & $>4$ & & & 0 & 1 & 2 & 3 & 4 & $>4$ \\
\hline $384 / 93$ & 7 & 4.6 & 19.2 & 76.2 & & & & $752 / 96$ & 7 & 3.5 & 15.3 & 79.7 & 1.5 & & \\
\hline $1 / \mathrm{m}$ & 8 & 2.0 & 21.2 & 74.8 & 2.0 & & & $8 / \mathrm{m}$ & 8 & 0.5 & 7.4 & 31.2 & 33.2 & 22.8 & 5.0 \\
\hline \multirow[t]{2}{*}{ Supratentorial } & 17 & 1.0 & 43.1 & 55.9 & & & & Cerebellum & 17 & & 6.7 & 83.9 & 7.3 & 2.1 & \\
\hline & TP53 & 14.7 & 58.8 & 26.5 & & & & & TP53 & 1.6 & 15 & 67.9 & 7.3 & v7.3 & 1.0 \\
\hline $486 / 93$ & 7 & 4.0 & 25.7 & 69.3 & 1.0 & & & $122 / 97$ & 7 & 1.7 & 15.7 & 81.0 & 1.7 & & \\
\hline $15 / \mathrm{m}$ & 8 & 5.9 & 23.8 & 68.3 & 1.0 & 1.0 & & $2 / f$ & 8 & 7.4 & 21.5 & 70.2 & 0.8 & & \\
\hline \multirow[t]{2}{*}{ Supratentorial } & 17 & 1.3 & 13.2 & 84.9 & 0.7 & 0.7 & & Cerebellum & 17 & 4.2 & 36.6 & 59.2 & & & \\
\hline & TP53 & 2.0 & 28.3 & 69.7 & 0.7 & & & & TP53 & & 47.9 & 52.1 & & & \\
\hline $91 / 94$ & 7 & 1.9 & 9.4 & 36.6 & 20.7 & 20.2 & 11.3 & $366 / 97^{b}$ & 7 & 0.5 & 25.0 & 72.0 & 2.5 & & \\
\hline $28 / \mathrm{m}$ & 8 & 2.3 & 23.9 & 64.8 & 6.1 & 1.9 & 0.9 & 12/f & 8 & 2.5 & 30.5 & 67.0 & & & \\
\hline \multirow[t]{2}{*}{ Cerebellum } & 17 & 0.0 & 8.0 & 84.5 & 6.0 & 1.5 & & Cerebellum & 17 & 0.3 & 25.4 & 71.2 & 3.0 & & \\
\hline & TP53 & 4.0 & 15.5 & 67.0 & 7.5 & 5.0 & 1.0 & & TP53 & 1.0 & 23.4 & 69.2 & 4.3 & 1.7 & 0.3 \\
\hline $287 / 94$ & 7 & 0.5 & 17.1 & 79.1 & 2.4 & 0.5 & 0.5 & $695 / 98$ & 7 & 1.5 & 26.0 & 68.5 & 2.0 & 2.0 & \\
\hline $20 / f$ & 8 & 1.9 & 12.3 & 82.9 & 1.4 & 1.4 & & $8 / \mathrm{f}$ & 8 & 3.0 & 32.5 & 61.5 & 2.0 & 1.0 & \\
\hline \multirow[t]{2}{*}{ Cerebellum } & 17 & & 5.5 & 85.5 & 6.0 & 3.0 & & Cerebellum & $17^{\mathrm{c}}$ & - & - & - & - & - & - \\
\hline & TP53 & 1.5 & 12.9 & 69.7 & 8.0 & 7.5 & 0.5 & & TP53 & & 18.9 & 77.6 & 2.1 & 1.4 & \\
\hline $1474 / 94$ & 7 & 0.9 & 8.0 & 75.0 & 12.5 & 3.6 & & $223 / 99$ & 7 & 3.5 & 28.5 & 66.0 & 2.0 & & \\
\hline $4 / \mathrm{m}$ & 8 & 1.8 & 11.6 & 77.7 & 6.3 & 2.7 & & $16 / \mathrm{m}$ & 8 & 7.0 & 29.5 & 63.5 & & & \\
\hline \multirow[t]{2}{*}{ Supratentorial } & 17 & 1.5 & 22.9 & 74.1 & 1.6 & & & Brainstem & 17 & 4.0 & 25.0 & 69.5 & 1.0 & 0.5 & \\
\hline & TP53 & 5.3 & 29.8 & 63.4 & 1.6 & & & & TP53 & 1.0 & 19.0 & 78.0 & 1.5 & & 0.5 \\
\hline $357 / 96$ & 7 & 0.5 & 6.0 & 54.2 & 27.4 & 9.0 & 3.0 & 998/99 & 7 & 1.1 & 19.0 & 72.5 & 4.9 & 1.9 & 0.5 \\
\hline $7 / \mathrm{m}$ & 8 & 1.0 & 8.0 & 58.2 & 24.4 & 6.0 & 2.5 & $10 / \mathrm{f}$ & 8 & 0.5 & 31.6 & 62.6 & 4.4 & 0.8 & \\
\hline \multirow[t]{2}{*}{ Cerebellum } & 17 & & 13.5 & 73.5 & 10.5 & 2.5 & & Cerebellum & 17 & & 13.9 & 79.1 & 4.7 & 1.7 & \\
\hline & TP53 & 2.5 & 17.5 & 65.5 & 7.0 & 7.0 & 0.5 & & TP53 & 0.6 & 17.4 & 74.1 & 5 & 2.3 & \\
\hline $508 / 96$ & 7 & 5.5 & 39.0 & 54.0 & 1.0 & & 0.5 & $1068 / 99$ & 7 & & 12.5 & 60.5 & 15.0 & 10.0 & 2.0 \\
\hline $11 / \mathrm{f}$ & 8 & 5.5 & 24.5 & 69.5 & 0.5 & & & $61 / \mathrm{m}$ & 8 & 1.5 & 18.5 & 56.5 & 13.5 & 8.0 & 2.0 \\
\hline \multirow[t]{2}{*}{ Cerebellum } & 17 & 0.3 & 22.8 & 76.4 & 0.5 & & & Brsainstem & 17 & 0.7 & 14.1 & 67.8 & 10.2 & 6.4 & 1.1 \\
\hline & TP53 & 2.2 & 21.7 & 73.4 & 1.4 & 1.1 & & & TP53 & 2.8 & 21.8 & 60.1 & 9.2 & 5.3 & 1.1 \\
\hline
\end{tabular}

${ }^{\mathrm{a}} \mathrm{m}$, male; f, female. ${ }^{\mathrm{b}}$ Recurrence of 508/96. ${ }^{\mathrm{c}}$ Not valuable due to intense background signal. Considering the results from control hybridizations we determined a cut-off level of $10 \%$, for monosomy 8 of $14 \%$ (printed in bold).

For CGH analysis 11 primary and 3 recurrent tumors and leptomeningal blood vessels of the same patients, as an internal control were analyzed (Table I). Archival routinely fixed (4\% neutral buffered formaldehyde) paraffin-embedded tumor samples were cut in serial sections, $10 \mu \mathrm{m}$ for microdissection, and $6 \mu \mathrm{m}$ for FISH, respectively. FISH analysis was performed on 13 primary tumors and 1 recurrent tumor (Table II). Six of these patients are not concordant with the CGH study because all available material was used up. All patients gave written informed consent for the use of the tumor samples for genetic analysis.

Microdissection, DOP-PCR, CGH. Microdissection, DOP$\mathrm{PCR}$, and CGH were performed as previously described (26).
In short, using an upright brightfield microscope (Olympus BX60, Tokyo, Japan) about 50-500 cells were dissected with DNA-free glass needles, attached to a mechanical micro-manipulator (Eppendorf, Germany) (Fig. 1). Histomorphologically normal appearing leptomeningeal blood vessels of the same tumor served as normal control tissue. After digestion the DNA was homogeneously amplified in a thermocycler (PTC 100, MJ Research, Waltham, MA) and labeled with biotin-16-dUTP (Roche Diagnostics, Germany) in a second amplification step. Normal reference DNA was labeled with digoxigenin by standard nick translation (Roche Diagnostics). The same amounts (600 ng) of tumor and normal DNA together with COT1 DNA (Roche Diagnostics) were hybridized to normal chromosome metaphase spreads 

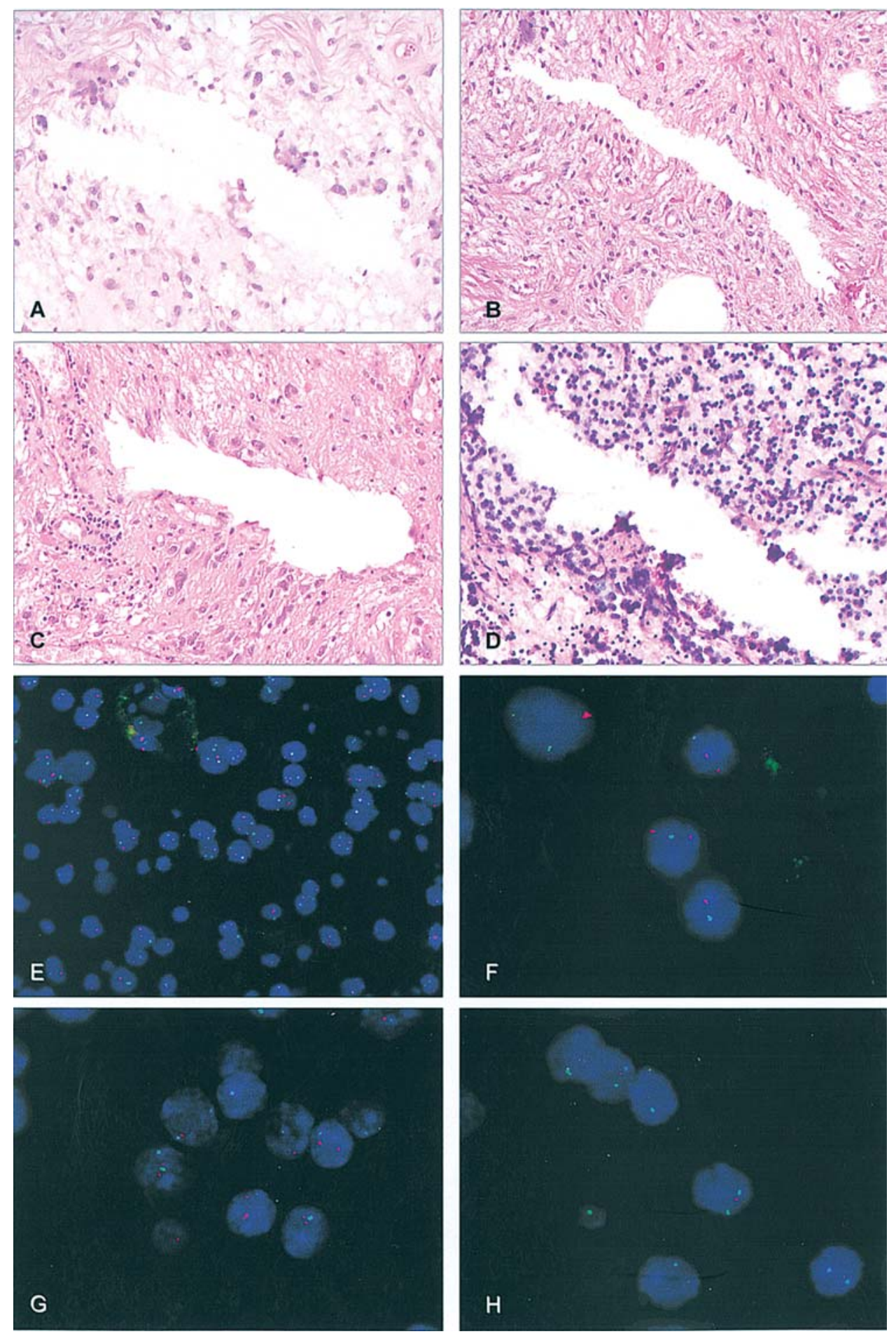

Figure 1. Pilocytic astrocytomas after microdissection. A, stellate cells in a micro-cystic background (tumor 57/97). B, bipolar cells in a fibrillary background (tumor 287/94). C, pleomorphic cells in a fibrillary background (tumor 91/94). D, pleomorphic area with multinuclear cells in a myxoid background (tumor 638/00). All sections were stained with hematoxylin and eosin, magnification x100. E and F show cell nuclei within a tissue section of case 223/99 and 998/99 hybridized with probes specific for the centromere regions of chromosome 7 (green) and 8 (red) (original magnification x60 and x100, respectively). The view field shows an overview about the heterogeneous distribution of the chromosomal aberrations (E), in (F) two nuclei with monosomy 7 and disomy 8 , one nuclei with monosomy 7 and 8 and one nuclei with monosomy 8 and disomy 7 are shown. G and H show cell nuclei within a tissue section of case 508/96 and 366/97 hybridized with probes specific for the centromere region of chromosome 17 (green) in combination with a single-copy probe for TP53 (red) (original magnification x100). The view field shows nuclei with a normal distribution for chromosome 17 and TP53 (in part with the second signal for chromosome 17 below the focus line) next to nuclei with heterozygous deletions for TP53 and two signals for chromosome 17 as well as nuclei with one chromosome 17 and one signal for TP53.

from peripheral blood lymphocytes prepared following standard procedures. After post hybridization washes, tumor DNA was visualized with fluorescein isothiocyanate (Vector Laboratories,
Burlingame, CA), and normal DNA with rhodamine (Roche Diagnostics). Fluorescence images were captured and processed by use of Isis (Metasystems, Germany). Average 
ratio profiles were determined from analysis of 10-15 metaphases. The thresholds used for ratio profiles were 1.2 for gain and 0.8 for loss.

\section{FISH}

Pretreatment and hybridization. Tumor tissue sections were deparaffinized and digested in proteinase $\mathrm{K}$ solution $(2 \mathrm{mg} / \mathrm{ml}$ proteinase $\mathrm{K}$ in $5 \mathrm{mM}$ EDTA/50 mM Tris $\mathrm{pH} 7.6$, Merck, Germany) at $55^{\circ} \mathrm{C}$. The sections were rinsed two times for $5 \mathrm{~min}$ in PBS at room temperature, incubated in 2X SSC for $30 \mathrm{~min}$ at $80^{\circ} \mathrm{C}$, dehydrated and air-dried (27).

Dual-probe hybridization was performed using a digoxigenin-labeled locus-specific probe for TP53 (Qbiogene, Illkirch, France), simultaneous with a biotin-labeled centromere-specific probe for chromosome 17 (D17Z1) on one section and a digoxigenin-labeled centromere-specific probe for chromosome 7 (pa7t1), simultaneous with a biotin-labeled probe for chromosome 8 (D8Z2) on a parallel section. D17Z1, $\mathrm{p} \alpha 7 \mathrm{t} 1$ and D8Z2 were purchased from ATCC (American Type Culture Collection, Rockville, MD).

Target DNA was denatured in $70 \%$ formamide/2X SSC at $70^{\circ} \mathrm{C}$ for $15 \mathrm{~min}$ and dehydrated in a series of cold alcohol $\left(-20^{\circ} \mathrm{C}\right)$. Probe DNA was denatured at $70^{\circ} \mathrm{C}$ for $5 \mathrm{~min}$, followed by incubation over two days at $37^{\circ} \mathrm{C}$.

Stringency washing and microscopy. Sections were washed two times in $2 \mathrm{X} \mathrm{SSC}$ at $42^{\circ} \mathrm{C}$ and three times in $57 \%$ formamide/2X SSC at $42^{\circ} \mathrm{C} 10 \mathrm{~min}$ each. Immunofluorescence detection of the biotin signals was carried out using Streptavidin-FITC and biotinylated anti-Streptavidin (Vector Laboratories). For the detection of the digoxigenin signals, anti-Dig-Cy3 and goat anti-mouse-Cy3 (Jackson Immuno-Research Laboratories, West Grove, PA) were used. The nuclei were counterstained with an anti-fade solution containing DAPI (4, 6-diamidino-2-phenylindole) (Vector Laboratories).

An Olympus BX 60 microscope was used to count the FISH signals. Approximately 200 non-overlapping nuclei were enumerated per hybridization according to the criteria of Hopman et al (28).

Hybridizing and enumerating non-neoplastic brain tissue from persons who had died without known neurological diseases was performed for cut-off ranges for all FISH probes. Alternatively, normal human lymphocytes were hybridized in parallel to supervise cross hybridizations by non-stringency of hybridization conditions. Tumors were classified as aneuploid when more than $10 \%$ of scored nuclei were monosomic or trisomic/polysomic. Due to reduced hybridization efficiency of the D8Z2 probe, the cut-off level for monosomy 8 was set to $14 \%$ while it was still $10 \%$ for trisomy 8 .

\section{Results}

CGH. From 14 pilocytic astrocytomas of 11 patients, 31 different areas were microdissected: 13 with the classical biphasic pattern, 8 with pleomorphic hallmarks like large hyper-chromatic nuclei, multinuclear cells or high cell density with myxoid change (Fig. 1) and 10 leptomeningeal blood vessels for internal control. All microdissected control tissues (10/10) showed a normal karyotype, whereas in 9/13
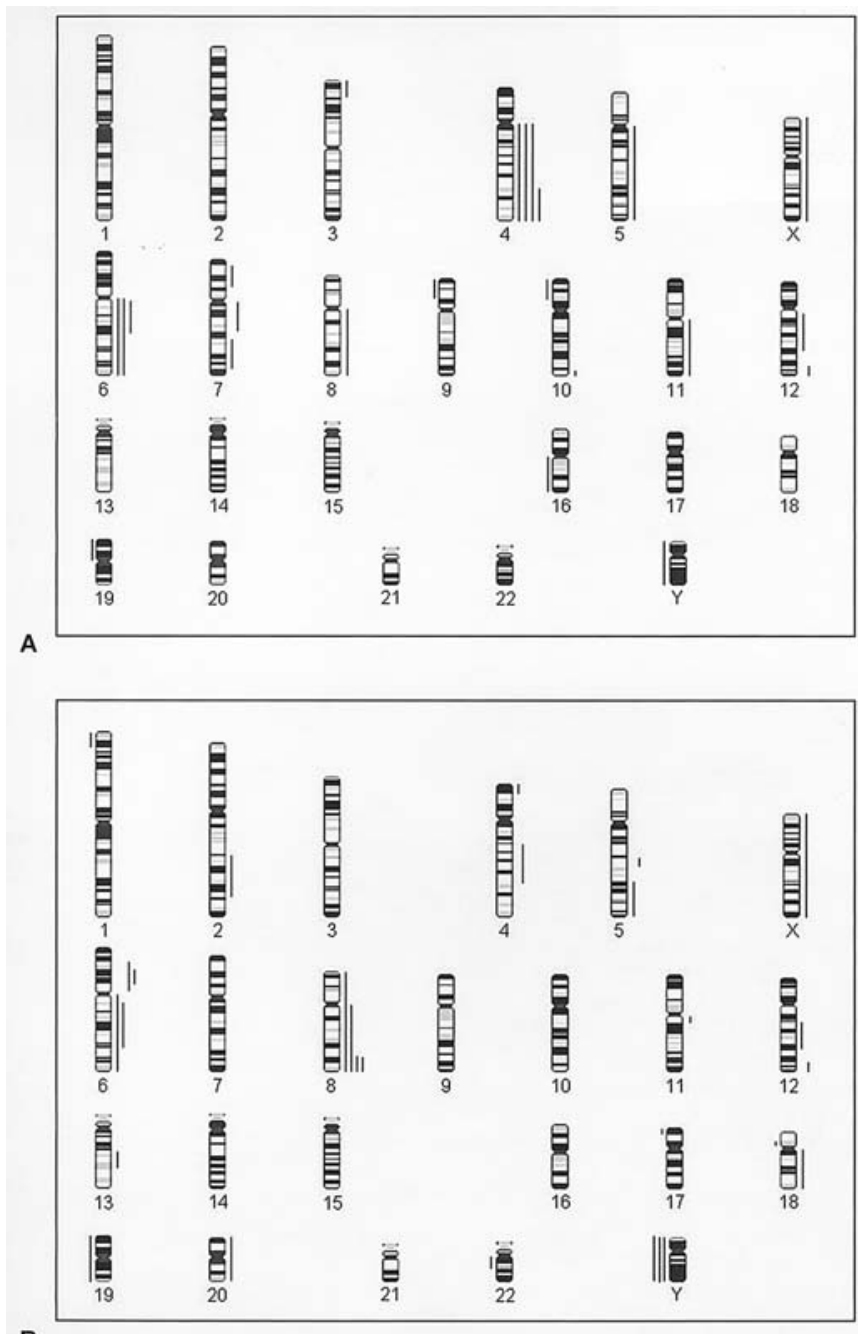

B

Figure 2. Distribution of chromosomal alterations in biphasic (A) and pleomorphic areas (B) of 14 pilocytic astrocytomas. Lines on the left of the chromosomes represent DNA losses, gains are on the right.

biphasic areas and 6/8 pleomorphic areas genetic changes were detected. Regardless of the different histomorphological pattern, most frequently gains were detected on chromosome arm 4q, 6q, 8q and 12q (Table I and Fig. 2). Thus, the tumors showed established chromosomal aberrations, as well as chromosomal aberrations, to date not known for pilocytic astrocytomas. In general, the pleomorphic areas showed more complex aberrations than the biphasic areas of the same tumors. The three recurrences (case 363/99, 1054/97, 638/00) revealed the same aberrations as the corresponding primary tumor, but also showed additional changes (see Table I).

With the exception of chromosomes 14, 15 and 21, all chromosomes were involved in genetic alterations. Most frequently, gains were detected on chromosome 4 (4 biphasic and 1 pleomorphic areas), on chromosome 6 (3 biphasic and 2 pleomorphic areas), on chromosome 8 (1 biphasic and 4 pleomorphic areas), and on chromosome 12 (2 biphasic and 2 pleomorphic areas).

Taking the histomorphology into account (Fig. 2), gains of chromosome arm 4q are mainly detected in biphasic areas, whereas gains on chromosome arm $8 \mathrm{q}$ are observed most often in pleomorphic areas. Gains on chromosome 6 were 


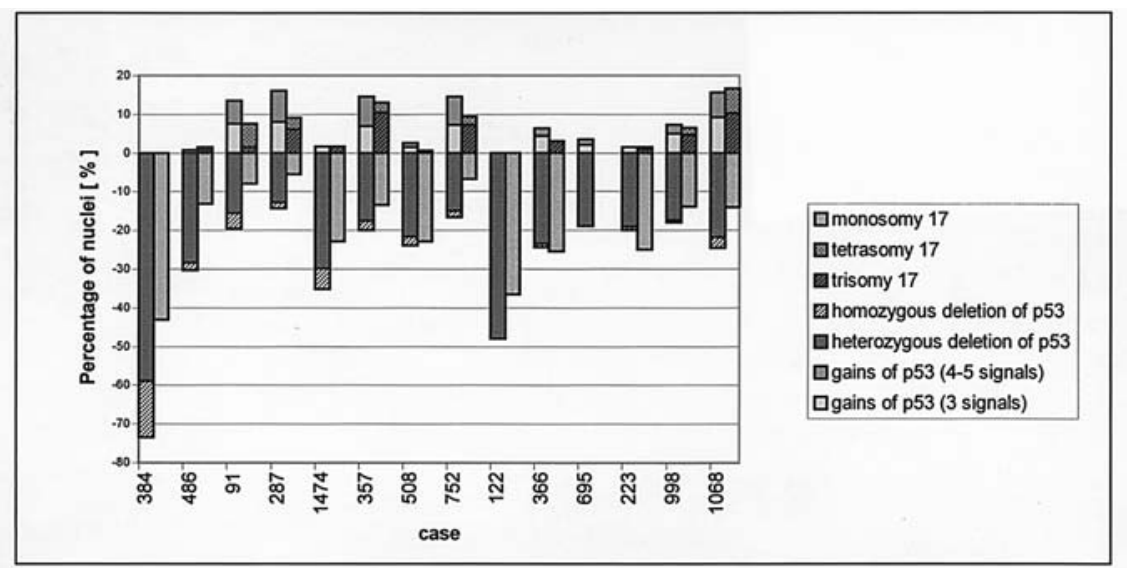

A

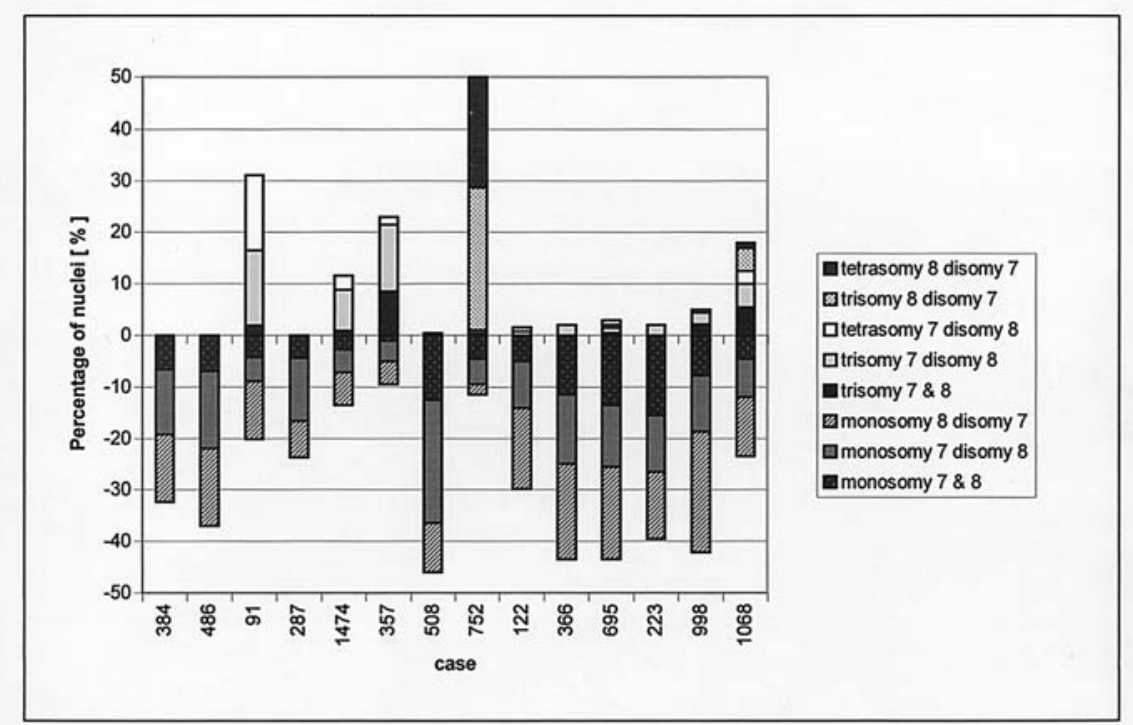

B

Figure 3. Summary of the most frequent simultaneous occurring aberrations detected by FISH.

found in biphasic as well as in pleomorphic areas. However, in biphasic areas only a gain of $6 \mathrm{q}$ was detected, whereas in pleomorphic areas the complete chromosome 6 was involved.

FISH. By interphase FISH, in all investigated (14/14) tumors, aneuploidies of all analyzed chromosomes were detected (Table II). Typical examples of the signal distribution in single nuclei are shown in Fig. 1 E-H.

In all tumors, cells with loss of TP53 were observed (15-59\% of nuclei). Furthermore, 10 tumors showed a significant proportion of cells with monosomy 17 (13-43\% of nuclei). One case (695/98) could not be analyzed for chromosome 17 because of high background fluorescence. Two cases also showed cells with gains of chromosome 17, the percentages, however, were near the cut-off level of $10 \%$.

The majority of tumors (10/14) showed significant numbers of cells with loss of one chromosome 7 (16-39\% of nuclei). Cells with gains of chromosome 7 were observed in 4/14 cases, whereas one case also showed adjacent cells with losses of chromosome 7.

Nine of 14 tumors only showed cells with loss of one chromosome 8 (21-33\% of nuclei). One tumor showed both cells with gains and losses of chromosome 8. Two tumors showed only gains and two tumors revealed no statistically significant aberrations of chromosome 8.

In one patient (case 508/96 and 366/97) with a recurrence, both the primary tumor and the recurrence showed losses of chromosome 7 in $39 \%$ of nuclei of the primary, and in $25 \%$ of the recurrent tumor. For chromosome 8 the ratio was $25 \%$ and $31 \%$ of nuclei.

Loss of chromosome 17 and heterozygous deletion of TP53 were detected in $23 \%$ and $22 \%$ of nuclei, and in the recurrence $25 \%$ and $23 \%$, respectively. All numerical chromosome aberrations were scattered diffusely throughout the evaluated areas (intratumoral heterogeneity) and did not show a clonal distribution.

Regarding the simultaneous occurrence of aberrations, monosomy 7 was observed in combination with either monosomy or disomy of chromosome 8 and vice versa (Fig. 3). Furthermore, gains of chromosome 7 were detected in combination with disomy 8 , and in a lower percentage of nuclei in combination with trisomy 8 . Only one tumor (case 752/96) showed gains of chromosome 8 in combination with two signals of chromosome 7 in the majority of cells. 


\section{Discussion}

During the past 20 years only few cytogenetic studies of pilocytic astrocytomas have been published. Most cases showed normal karyotypes, and in contrast to other gliomas, fewer random structural and numerical chromosomal abnormalities. Altogether, only a slight increase in aneuploidy for chromosomes 7, 8 and 11 was observed (3-11,30). Generally, chromosomal alterations are only detectable when they occur in the majority of tumor cells and/or are favored by in vitro selection in cell cultures. Therefore, genetic alterations which occur only in a lower frequency of tumor cells or are prone to be lost in vitro, are not detected. Our present data actually demonstrate partial chromosomal gains and losses which are only rarely or not observed by metaphase analysis of these tumors.

The most important observation of the microdissection study with CGH was that some alterations show areaspecificity. In general, pleomorphic areas showed both more, and more complex aberrations than bipolar areas of the same tumor. Gains of $4 q$ and $6 q$ appeared to be more pronounced in biphasic areas, whereas gains of 6 and $8 \mathrm{q}$ seemed to be more common in pleomorphic areas. These genetic aberrations are confirmed by $\mathrm{CGH}$ studies on homogenized tumor samples in a lower frequency (12-15) and are also observed in low grade astrocytomas (30). With this specific approach it was possible to show the first evidence of a correlation of different morphologic areas with specific genetic changes. Gains on chromosomes $4 \mathrm{q}$ and 6 were reported previously to also occur in high-grade gliomas (26). In contrast to pilocytic astrocytomas, in the genetically heterogeneous glioblastomas no correlation to histomorphological differences was detected $(26,31)$.

A correlation of tumor specific abnormalities to different histomorphological areas and the low frequency of changes could explain the differences of the described data to cell culture experiments (4-11). The genetic changes detected by FISH could be confirmed by CGH in only one case (752/96), because of the lower resolution of the $\mathrm{CGH}$ which detects only genetic changes when more than $40-50 \%$ of the tumor cells are affected.

Gains of chromosome 7 and 8 were also reported by FISH analysis of isolated nuclei from paraffin-embedded tissue (16). In the two-color FISH study, 8 cases showed cells with trisomy 7, and 6 of them with trisomy 8 . Moreover, in contrast to previous studies, it was also possible to detect losses of chromosomes 7 and 8 in a large amount of cells of the same tumors. The majority of cases showed losses and one tumor showed losses as well as gains for chromosome 7 . This case (1068/99) showed gains and losses for chromosome 8, and in 9 tumors, only losses for chromosome 8 were found.

The tumors showed numerical aberrations of chromosome 7 and 8 in a scattered distribution through the tumor tissue. One possible explanation for these findings might be an increased de novo non-disjunction in these tumors revealed by the high resolution of the method used. Nearly all reports concerning chromosome 7 in astrocytomas are derived from cell culture results. It is discussed that gain of chromosome 7 might have a proliferation advantage in cell culture leading to artifacts (29). Losses of chromosomes 7 and 8 are also reported in the above-mentioned FISH-study on isolated nuclei of paraffin-embedded tumor tissue, but because of a high cut-off level these results were not considered as relevant by the authors (16). Gains and losses of chromosome 8 within the same as well as in different tumors were described also for high grade gliomas, suggesting an intra- and interspecific heterogeneity (31). FISH gave evidence that native tumor cells display a higher variation of numerical aberrations of theses chromosomes than cell cultures. This might occur due to a general numerical chromosome in vivo instablility that, as a result of clonal selection under in vitro conditions, is less obvious. These findings, as well as the described results, show that it is possible to identify more cytogenetic alterations in pilocytic astrocytomas when alternative techniques, instead of conventional cytogenetic methods were used. For chromosomes 7 and 8, gains as well as losses, adjoining specific molecular cytogenetic inconspicuous nuclei are observed in the same tumor which explains the heretofore rarely observed chromosomal alterations in pilocytic astrocytomas.

Interestingly, for these low grade tumors, heterozygous deletions of TP53 were detected in all investigated biopsies; additionally monosomy 17 was found in 10/14 cases. This signifies a much higher rate of TP53 deletions than published before. Most authors rarely observed mutations or LOH of TP53 in pilocytic astrocytomas $(3,17,19-21)$. Only one publication (18) reported a higher percentage (35\% of investigated tumors) of TP53 mutations. These observations confirm that chromosomal aberrations and molecular alterations present only in specific intratumoral structures, in a minority of cells, or balancing each other (e.g. cells with gain and cells with loss of the same chromosome), may be missed when only tumor homogenates are investigated. TP53 mutations are known to play an important role in the genetic pathway leading to secondary glioblastomas and were detetected already in low grade astrocytomas. Our present data indicate a major impact of TP53 alterations also in pilocytic astrocytomas. Moreover, this study demonstrates that intratumoral genetic heterogeneity as reported for higher grade gliomas (30) can also be detected with appropriate techniques, even at a lower ratio in low grade pilocytic astrocytomas.

\section{Acknowledgements}

This study was supported by grant of the Deutsche Forschungsgemeinschaft (SFB 399 A3).

\section{References}

1. Giannini C and Scheithauer BW: Classification and grading of low-grade astrocytic tumors in children. Brain Pathol 7: 785-798, 1997.

2. Kleihues P and Cavenee WK (eds): Pathology and Genetics of Tumors of the Nervous System. World Health Organization Classification of Tumours. IARC Press, Lyon, 2000.

3. Cheng Y, Pang JC, Ng HK, Ding M, Zhang SF, Zheng J, Liu DG and Poon WS: Pilocytic astrocytomas do not show most of the genetic changes commonly seen in diffuse astrocytomas. Histopathology 37: 437-444, 2000.

4. Ransom DT, Ritland SR, Kimmel DW, Moertel CA, Dahl RJ, Scheithauer BW, Kelly PJ and Jenkins RB: Cytogenetic and loss of heterozygosity studies in ependymomas, pilocytic astrocytomas, and oligodendrogliomas. Genes Chromosomes Cancer 5: 348-356, 1992 . 
5. Karnes PS, Tran TN, Cui MY, Raffel C, Gilles FH, Barranger JA and Ying KL: Cytogenetic analysis of 39 pediatric central nervous system tumors. Cancer Genet Cytogenet 59: 12-19, 1992.

6. Thiel G, Losanowa T, Kintzel D, Nisch G, Martin H, Vorpahl K and Witkowski R: Karyotypes in 90 human gliomas. Cancer Genet Cytogenet 58: 109-120, 1992.

7. Zattara-Cannoni H, Gambarelli D, Lena G, Dufour H, Choux M, Grisoli F and Vagner-Capodano AM: Are juvenile pilocytic astrocytomas benign tumors? A cytogenetic study in 24 cases. Cancer Genet Cytogenet 104: 157-160, 1998.

8. Agamanolis DP and Malone JM: Chromosomal abnormalities in 47 pediatric brain tumors. Cancer Genet Cytogenet 81: 125-134, 1995.

9. Bigner SH, McLendon RE, Fuchs H, McKeever PE and Friedman HS: Chromosomal characteristics of childhood brain tumors. Cancer Genet Cytogenet 97: 125-134, 1997.

10. Bhattacharjee MB, Armstrong DD, Vogel H and Cooley LD: Cytogenetic analysis of 120 primary pediatric brain tumors and literature review. Cancer Genet Cytogenet 97: 39-53, 1997.

11. Jenkins RB, Kimmel DW, Moertel CA, Schultz CG, Scheithauer BW, Kelly PJ and Dewald GW: A cytogenetic study of 53 human gliomas. Cancer Genet Cytogenet 39: 253-279, 1989.

12. Sanoudou D, Tingby O, Ferguson-Smith MA, Collins VP and Coleman N: Analysis of pilocytic astrocytoma by comparative genomic hybridization. Br J Cancer 82: 1218-1222, 2000.

13. Shlomit R, Ayala AG, Michal D, Ninett A, Frida S, Boleslaw G, Gad B, Gideon R and Shlomi C: Gains and losses of DNA sequences in childhood brain tumors analyzed by comparative genomic hybridization. Cancer Genet Cytogenet 121: 67-72, 2000.

14. Warr T, Ward S, Burrows J, Harding B, Wilkins P, Harkness W, Hayward R, Darling J and Thomas D: Identification of extensive genomic loss and gain by comparative genomic hybridisation in malignant astrocytoma in children and young adults. Genes Chromosomes Cancer 31: 15-22, 2001.

15. Szymas J, Wolf G, Petersen S, Schluens K, Nowak S and Petersen I: Comparative genomic hybridization indicating two distinct subgroups of pilocytic astrocytomas. Neurosurg Focus 8: $1-6,2000$.

16. White FV, Anthony DC, Yunis EJ, Tarbell NJ, Scott RM and Schofield DE: Nonrandom chromosomal gains in pilocytic astrocytomas of childhood. Hum Pathol 26: 979-986, 1995.

17. Willert JR, Daneshvar L, Sheffield VC and Cogen PH: Deletion of chromosome arm 17p DNA sequences in pediatric highgrade and juvenile pilocytic astrocytomas. Genes Chromosomes Cancer 12: 165-172, 1995

18. Hayes VM, Dirven CM, Dam A, Verlind E, Molenaar WM, Mooij JJ, Hofstra RM and Buys CG: High frequency of TP53 mutations in juvenile pilocytic astrocytomas indicates role of TP53 in the development of these tumors. Brain Pathol 9: 463-467, 1999.
19. Collins VP: Gliomas. Cancer Surv 32: 37-51, 1998

20. Von Deimling A, Fimmers R, Schmidt MC, et al: Comprehensive allelotype and genetic anaysis of 466 human nervous system tumors. J Neuropathol Exp Neurol 59: 544-558, 2000.

21. Von Eckardstein K, Gries H, Bolik E, Cervos-Navarro J, Tschairkin IN and Patt S: p53 mutation and protein alteration in 50 gliomas. Retrospective study by DNA-sequencing techniques and immunohistochemistry. Histol Histopathol 12: 611-616, 1997.

22. Ishii N, Sawamura Y, Tada M, Daub DM, Janzer RC, MeagherVillemure M, De Tribolet N and van Meir EG: Absence of p53 gene mutations in a tumor panel representative of pilocytic astrocytoma diversity using a p53 functional assay. Int J Cancer 76: 797-800, 1998 .

23. Von Deimling A, Louis DN, Menon AG, von Ammon K, Petersen I, Ellison D, Wiestler OD and Seizinger BR: Deletions on the long arm of chromosome 17 in pilocytic astrocytoma. Acta Neuropathol 86: 81-85, 1993.

24. Platten M, Giordano MJ, Dirven CM, Gutmann DH and Louis DN: Up-regulation of specific NF 1 gene transcripts in sporadic pilocytic astrocytomas. Am J Pathol 149: 621-627, 1996.

25. Scheurlen WG and Senf L: Analysis of the GAP-related domain of the neurofibromatosis type 1 (NF1) gene in childhood brain tumors. Int J Cancer 64: 234-238, 1995.

26. Jung V, Romeike BF, Henn W, Feiden W, Moringlane JR, Zang KD and Urbschat S: Evidence of focal genetic microheterogeneity in glioblastoma multiforme by area-specific CGH on microdissected tumor cells. J Neuropathol Exp Neurol 58: 993-999, 1999.

27. Lutz S, Welter C, Zang KD, Seitz G, Blin N and Urbschat K: A two-colour technique for chromosome in situ hybridization in tissue sections. J Pathol 167: 279-282, 1992.

28. Hopman AH, Ramaekers FC, Raap AK, Beck JL, Devilee P, van der Ploeg M and Vooijs GP: In situ hybridization as a tool to study numerical chromosome aberrations in solid bladder tumors. Histochemistry 89: 307-316, 1988.

29. Mondello C, Moralli D, Franceschi C and Nuzzo F: Occurrence and expansion of trisomy 7 in a fibroblast strain from a centenarian individual. Exp Gerontol 34: 715-719, 1999.

30. Nishizaki T, Ozaki S, Harada K, Ito H, Arai H, Bepppu T and Sasaki K: Investigation of genetic alterations associated with the grade of astrocytic tumor by comparative genomic hybridization. Genes Chromosomes Cancer 21: 340-346, 1998

31. Loeper S, Romeike BFM, Heckmann N, Jung V, Henn W, Feiden W, Zang KD and Urbschat S: Frequent mitotic errors in tumor cells of genetically micro-heterogeneous glioblastomas. Cytogenetic Cell Genetic 94: 1-8, 2001. 